\title{
Effects of Brand on Consumer Preferences: A study in Turkmenistan
}

\author{
Abdurrahman ISIK*, Mehmet Fatih YASAR ${ }^{* *}$
}

\begin{abstract}
Using a measurement model of brand name and consumer preferences, this study aims to investigate the effects of brand name on consumer preferences in Turkmenistan. This study sought to investigate specifically, the influence of brand name on consumer's preferences by utilizing structural equation modeling (SEM) technique. Moreover, all possible correlations between these dimensions or domains of brand name and consumer preferences are also empirically tested. In the context of the study, the introduced model was tested by a questionnaire instrument with 10 items excluding the demographic variables. A total of 422 completed copies of questionnaires were evaluated for analysis. The results suggest that, brand name variable have statistically significant relationships with consumer preferences variable. The findings of the study indicated positive correlations among the two variables with high factor loadings. Brand name of a product has significant impact on the overall preferences of the consumers.
\end{abstract}

Keywords: Brand, Consumer Preferences, Turkmenistan

JEL Code Classification: M20, M31

UDC: $339.13(575.4)$

\footnotetext{
* Nigerian Turkish Nile University, Nigeria. E-mail: a.isik@ntnu.edu.ng

** Corresponding Author, Nigerian Turkish Nile University, Nigeria. E-mail: mfyasar@ntnu.edu.ng 


\section{Introduction}

In a world where every product is bigger or better compared to its competitors, consumers have begun to face an important problem: the increased uncertainty about various products attributes. This arises from various asymmetric information consumers have access to, regarding a specific product. Consumers tend to asses certain product attributes in a holistically manner rather than a case by case basis (Ainslie \& Rossi, 1998). Therefore both extrinsic and intrinsic factors must be accounted when trying to differentiate a product from its competitors. In these circumstances, brands can potentially play many different roles in the consumer decision process. (Romani et al. 2012) shows that consumers' psychological, sociological and economic processes are simultaneously involved in choice behavior. In these days, a product or a service is almost irrelevant without the brand. It cannot be identified or associated with what influences in fact our purchasing process (Mindrut et al. 2015). The study of consumer's behavior and the attempt to model the decision-making process of consumers is a longstanding interest for marketing and decision theory scientists (Matsatsinis \& Samaras, 2000). Consumer-brand relationships (CBR) are important for the profitability of companies and enhancing the understanding of $\mathrm{CBR}$ is of great interest to researchers.

An organisation's brand image can be as important as the goods or services it produces. A strong brand image is a powerful asset. A recognised and trusted brand identity makes people confident that the organisation is dependable. Developing a corporate brand is important because a positive brand image will give consumers, and other interested stakeholders, confidence about the full range of products and activities associated with a particular company. Therefore, it was aimed in this study to investigate the relative influence of the brand image on consumer preferences and the formation of strong consumer preferences-brand relationships in Turkmenistan.

The present study sought to answer following research question by using Structural Equation Modeling (SEM): how brand affects the preferences of the consumers. The paper, first discusses the concept of brand and the potential contribution of brands in the consumer preferences. It then focuses on the brand's impact on consumer's favor, proposes the research questions, and outlines the data collection methods. Finally, it offers discussion, conclusion and suggestions for managers and academia. The value of this paper is that, this is the first study to investigate brand on consumer preference perception in Turkmenistan, and not many studies conducted in this area. Also, it provides practical guidance to business leaders for developing a successful strategy to develop a brand image. 


\section{Literature Review}

\subsection{Brand}

Consumer perception towards brand is an important aspect of marketing mix (Gabor \& Contiu, 2012). Jin and Weber (2013) proposed that, brands served primarily as a way for customers to identify and recognize goods and their manufacturer. The focus of brand value creation was on individual goods whereby firms used brands to show ownership and take responsibility for their goods. This in turn helped customers identify and recognize a firm's goods on sight. From the 1930s onwards, brands were viewed as images that firms create to enable customers to both differentiate a brand from its competitors and identify the needs a brand promises to satisfy (Jin \& Weber, 2013).

Another aspect of brand is that, it is strongly believed by academics and practitioners that brand reputation is becoming increasingly important. Brands should have a positive reputation to be successful and therefore profitable, (Veloutsou \& Moutinho, 2009). On the other hand, Schmitt (2012) describes a comprehensive model of five brand-related processes: identifying, experiencing, integrating, signaling and connecting with the brand.

The personal experience of using a brand can be of assorted shapes from the personal experience of using an indistinguishable product without the brand (Sheena \& Naresh, 2012). Brands can form relations with other brands. Brands can be anthropomorphized, and many of them are appreciated as cultural symbols. Finally, consumers can organize communities around brands. Consumers know and experience these characteristics about brands and respond to them. The model presented here accounts for these essential characteristics of brands (Schmitt, 2012).

\subsection{Consumer Preferences}

A broad variety of efforts and theories that attempt to describe the factors which influence the consumers and their behaviours when making purchasing decisions. The goal of the investigation of consumer behavior is to discover patterns of consumers' attitudes in their decision to buy or to ignore a product. (Matsatsinis, Samaras, 2000). Consumers' preferences for products or brands arise from the combination of many different factors. Some factors come from features of the product itself (e.g., price, durability), while others are attributes of consumers themselves (e.g., goals, attitudes, discretionary income), (Venkatraman, Clithero, Fitzsimons, and Huettel, 2012).

$\mathrm{Ge}$, Brigden and Häubl (2015) proposed that consumers often make choices in settings where some alternatives are known and additional alternatives can be unveiled through search. When making a choice from a set of alternatives, the manner in which each of these was discovered should be irrelevant from a normative standpoint. Consumers must often decide between choosing among a 
set of previously discovered alternatives and searching to discover additional alternatives before making a choice. A substantial body of prior work examines consumer choice from pre-determined sets of alternatives. As a result, we know much about the influence of choice set composition and decision context on choice (Ge, Brigden, and Häubl, 2015). Aditionally, consumer characteristics such as patriotism, protectionism and social economic conservatism are effecting their choices (Spillan \& Harcar, 2010).

\subsection{Brand and Consumer Preferences}

Often, consumers will tend to choose a brand that they consider congruent with their self-image. In this particular way each consumer at an individual basis will try to reflect his or her own identity through choice. When part of a larger social group, consumer choices tend to converge to a certain pattern thus forming the basics of an individual social identity (Cătălin, Andreea, 2014).

Brand preference is regarded as a key step in consumer decision making, involving elements of choice. In establishing brand preference, consumers compare and rank different brands by focusing on their uniqueness defined brand preference as "the extent to which the customer favors the designed service provided by his or her present company, in comparison to the designated service provided by other companies in his or her consideration set," with a consideration set referring to brands that a consumer would consider buying in the near future (Jin \& Weber, 2013). Also, customer's advisory has a positive effect on establishing a positive effect on brand and consumer preferences (Güngör \& Bilgin, 2011).

\subsection{Theorethical Framework}

The theory of consumer choice was used as the theoretical frameworks for this study. Main assumption of this theory is that, consumer fully understands their own preferences, allowing for a simple but accurate comparison between any two bundles of good presented. All consumers seek to maximize utility. In the mainstream economics tradition, this activity of maximizing utility has been deemed as the "rational" behavior of decision makers (Varian, 2006). Consumer theory is therefore based around the problem of generate refutable hypotheses about the nature of consumer demand from this behavioral postulate. The crux of the matter is that the role of brand concept and consumer preferences cannot be over-emphasized in Turkmenistan.

\subsection{Study Hypothesis}

The essential predictions associated with this brand and consumer preferences effect of research captured by the following research hypothesis which was formulated to be tested based on the theoretical framework of the study and the findings of the literature review;

$H_{1}$ : There is a positive linear relationship between brand and consumer preferences. 


\subsection{Theoretical Model}

This study has two latent variables, one exogenous variable, one endogenous variable. The conceptual model of this study is presented in Figure 1.

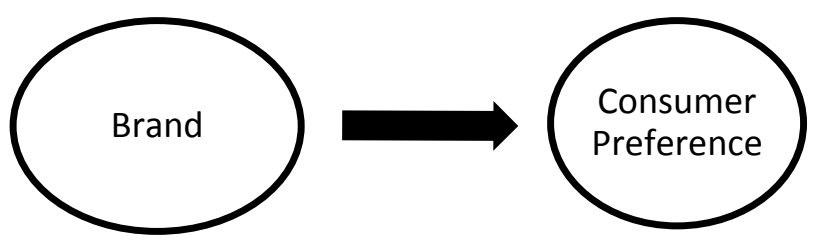

Figure 1: Hypothesized Model

\section{Methodology}

\subsection{Study Design and Sample}

The research was conducted in Turkmenistan. Approximately 600 hardcopies of questionnaires were delivered in person by the designated research assistants randomly using a simple random sampling method. The participants were provided two options for returning the copies of questionnaires: return their questionnaires to the designated research assistants in person, or to use the stamped envelope provided on which the return address was written. A total of 527 survey forms were collected and 105 survey forms were excluded from the analysis due to missing data. Thus, exactly 422 (80\%) complete forms were evaluated for further analysis. All data was collected in 2014.

\subsection{The survey instrument}

The survey instrument consisted of questions derived from the literature. There were 5 questions in brand section, and 5 questions in the consumer preference section. Also, the survey instrument consisted of a demographic information section.

a) Demographic Information: Information about the demographic characteristics of the participants was collected covering their, age, gender, marital status, income, education level and occupation.

b) Brand Scale: The indicators of brand section were developed by Isik (2013). To be used in numerous studies have confirmed its validity and reliability as a measure of Brand. The Brand variable was measured using 5 questions (see Appendix A). A five-point Likert scale was used for each of the 5 questions, scored from 1 to 5 where the number (1) means Strongly Disagree, (2) Disagree, (3) Neutral, (4) Agree, and (5) Strongly Agree. The five-point Likert scale was again used for all these questions. The Cronbach's alpha score for brand was 0.77 . Skewness and Kurtosis scores are between -1 and +1 which indicate that the distribution is normal. 
c) Consumer Preference Scale: Consumer preferences section indicators were developed by Isik (2013) and was measured using 5 questions (see Appendix A). A five-point Likert scale was used for each of the 5 questions, scored from 1 to 5 where the number (1) means Strongly Disagree, (2) Disagree, (3) Neutral, (4) Agree, (5) Strongly Agree. The five-point Likert scale was again used for all these questions. The Cronbach's alpha score was 0.70. Skewness and Kurtosis scores are between -1 and +1 which indicate that it has a normal distribution.

\subsection{Analysis}

The SPSS 18.0 software was used to assess the data. The Structural Equation Model (SEM), using AMOS 18.0 software program, was used to analyze the data. Structural Equation Model (SEM), a statistical process that evaluate how well the collected sample data fit to the theoretically driven developed model. Unlike other statistical analyses, using SEM in data analysis has the strength to extract measurement error from estimates of observed variables, which provides more accuracy in estimating the strength and degree of relationship (Byrne, 2001). Kula (2011) indicates the advantages of SEM that, it technique which allows the researcher to simultaneously estimate a measurement model, specifying relations between measured variables and underlying latent variables. SEM consists of measurement models of exogenous and endogenous variables, and control variables to investigate the structural relationship between them. The literature suggests that various goodness-of-fit indices can be used for Structural Equation Modeling (Byrne, 2010: Kline, 2011). The following indices are the most commonly used goodness-of-fit statistics in the related literature: $\chi 2-p-\chi 2 / d f$, RMSEA-PCLOSE, TLICFI values and HOLTER Index value (Uryan, 2010: 70-73; Kula, 2011: 65-74). The significance level for acceptance was set as $p<0.05$.

\section{Findings}

\subsection{Demographic variables}

This study has six demographic variables: age, gender, marital status, income, education level and occupation.. The distribution of the respondents over the demographic variables is presented in Table 1. A total of 422 employees participated to the survey. As displayed in Table 1, surprisingly, the majority of the study participants were female $(213 ; 50.5 \%)$, while male respondents constitute $40.5 \%$ (209). For the distribution of the respondents in terms of age, 255 respondents were relatively young with, 16-24 years old, and the next largest group, 70, was 35-49 years old. These two groups account for $60.4 \%$ and $16.6 \%$ respectively. 69 respondents (16.4\%) were ages $25-34$. The age group 50 years or older was the smallest, with 28 respondents (6.6\%).The distribution of the 422 respondents over marital status variable, 261 (63.5\%) respondent is single, while 72 (35.5\%) respondent is married. In terms of education level of respondents, 272 people had bachelor degree, 6 of them had master and Ph.D. degrees. Cumulatively, these two groups of people account for approximately $63.1 \%$ and 
$1.4 \%$ respectively. Those respondents with primary school degrees are 150 (35.5 $\%)$. In terms of respondents' occupation, 233 of the total 422 respondents (55.2\%) were students, 93 of the total respondents (22.0\%) were employees, and 52 of the total respondents (11.9\%) were entrepreneurs. Remaining $10.9 \%$ of the respondents were others. Majority of the respondents in terms of income level, 228 (54.4) of the total 422 respondents were between 0 and 500.82 respondents were in 501-1000, 45 respondents were in 1001-1500, 39 respondents were in 1501-2000. The percentage distributions of these three groups by income level were $19.0 \%, 10.7 \%$, and $9.2 \%$, respectively. Finally, only $6.6 \%$ (28) of the total respondents have 2000 and above income level.

Table 1. Demographic variables

\begin{tabular}{|c|c|c|}
\hline Variable & Frequency & Percentage (\%) \\
\hline \multicolumn{3}{|l|}{ Age } \\
\hline $16-24$ & 255 & 60.4 \\
\hline $25-34$ & 69 & 16.4 \\
\hline $35-49$ & 70 & 16.6 \\
\hline 50 and above & 28 & 6.6 \\
\hline \multicolumn{3}{|l|}{ Gender } \\
\hline Female & 213 & 50.5 \\
\hline Male & 209 & 49.5 \\
\hline \multicolumn{3}{|l|}{ Marital Status } \\
\hline Married & 154 & 36.5 \\
\hline Single & 261 & 63.5 \\
\hline \multicolumn{3}{|l|}{ Education } \\
\hline Primary school & 150 & 35.5 \\
\hline Bachelor & 266 & 63.1 \\
\hline Master / PhD & 6 & 1.4 \\
\hline \multicolumn{3}{|l|}{ Occupation } \\
\hline Student & 233 & 55.2 \\
\hline Employee & 93 & 22.0 \\
\hline Entrepreneur & 52 & 11.9 \\
\hline Other & 46 & 10.9 \\
\hline \multicolumn{3}{|l|}{ Income Level } \\
\hline $0-500$ & 228 & 54.4 \\
\hline $501-1000$ & 82 & 19.0 \\
\hline $1001-1500$ & 45 & 10.7 \\
\hline $1501-2000$ & 39 & 9.2 \\
\hline 2000 and above & 28 & 6.6 \\
\hline
\end{tabular}

The measurement models of the latent variables studied were validated. Then, they were put into a structural model with control variables of the study. After running the structural model, the generic model was revised since it did not fit the 
data well. The goodness of values of generic and revised models (Schumacker and Lomax, 2004, p.82; Schreiber et al., 2006) are demonstrated in the Table 2.

Table 2. Goodness of Fit Statistics of Generic and Revised Models

\begin{tabular}{|c|c|c|c|}
\hline Index & Criteria & Generic Model & Revised Model \\
\hline Chi-square $(\chi 2)$ & Low & 82.524 & 69.960 \\
\hline $\begin{array}{l}\text { Chi-square associated } p \\
\text { value }(p)\end{array}$ & $\geq .05$ & 0.000 & 0.003 \\
\hline Likelihood Ratio ( $\chi 2 / d f)$ & $\leq 4$ & 1.919 & 1.706 \\
\hline $\begin{array}{l}\text { Root Mean Square Error } \\
\text { of Approximation (RMSEA) }\end{array}$ & $\begin{array}{l}.05<\text { value } \leq .08 ; \text { acceptable } \\
\leq .05 ; \text { good }\end{array}$ & 0.047 & 0.041 \\
\hline $\begin{array}{l}\text { RMSEA associated } p \text { value } \\
\text { (PCLOSE) }\end{array}$ & $\geq .05$ & 0.619 & 0.811 \\
\hline Tucker-Lewis Index (TLI) & $\begin{array}{l}.90 \leq \text { value }<.95 \text { acceptable; } \\
\geq .95 \text { good }\end{array}$ & 0.947 & 0.959 \\
\hline $\begin{array}{l}\text { Comparative Fit Index } \\
\text { (CFI) }\end{array}$ & $\begin{array}{l}.90 \leq \text { value }<.95 \text { acceptable } \\
\geq .95 \text { good }\end{array}$ & 0.959 & 0.970 \\
\hline $\begin{array}{l}\text { Hoelter's Critical N } \\
\text { (Hoelter Index) }\end{array}$ & $\begin{array}{l}75 \leq \text { value }<200 \text { acceptable } \\
\geq 200 \text { good }\end{array}$ & 303 & 343 \\
\hline
\end{tabular}

Brand and consumer preference are not exactly measured (latent) variables. Structural Equation Model was used to investigate the relationship between the two variables.

The goodness-of-fit statistics for both generic (hypothesized) and revised SEM models are presented in Table 2. All critical ratios in the revised model were statistically significant $(p \leq .05)$. The revised model produced better goodness-of-fit scores. The model improvement can be clearly observed in Table 2 . The chi-square difference between the generic and revised model was 12.564, indicating that the chi-square value significantly decreased in the revised model. Significant improvements were also observed for the chi-square likelihood ratio and the RMSEA value. While the likelihood ratio went down from 1.919 to 1.706 , an important change was observed in root mean square error of approximation (RMSEA) value which decreased from .047 to .041.

The only goodness-of-fit statistic not within acceptable limits was the chi-square $p$ value (.000). It was found to be lower than the suggested level (.05). However, the probability value may be misleading because it is sensitive to sample size. When the sample size is large, the chi-square probability value tends to be significant even if there is a small difference between the covariance structure of the hypothesized model and the observed covariance matrix (Byrne, 2001). Additionally, "it is sensitive to the size of correlations: bigger correlations generally lead to higher values of chi-square" (Sahin, 2010, p. 131).

Because of the reasons explained above, many researchers believe that chi-square statistics such as probability value should not be the only criteria for model fit 
decisions in SEM analyses. Therefore, it is recommended that along with the chisquare test, other goodness-of-fit tests such as the RMSEA and CFI also be used for a reliable assessment (Schumaker and Lomax, 2004).

A substantial improvement was achieved for the TLI, CFI and Hoelter Index scores of the revised model compared to generic model. While TLI scores increased from .94 to .96 , which indicates perfect model fit, the CFI value rose to .96 from .97, indicating a perfectly model fit. Hoelter index value of 343 (compared to 303 in the generic model) in the revised model demonstrates that the revised model has adequate sample size at the determined threshold level.

Overall, results revealed that the revised Structural Equation Modelling model provided an adequate model fit, meaning that the Structural Equation Modelling fit the data well.

The revised structural equation model is presented in Figure 2.

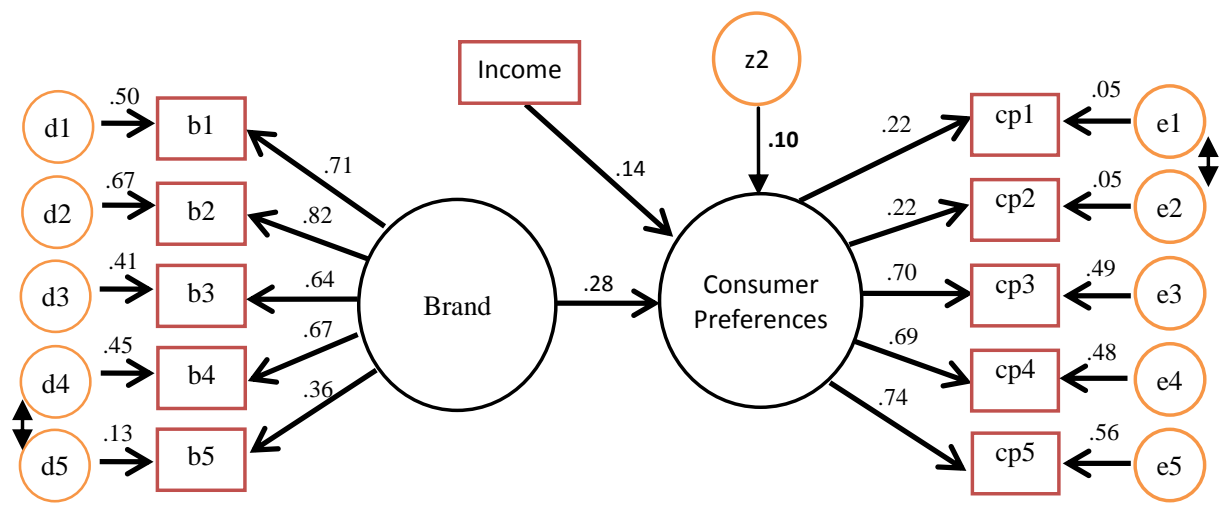

\section{Figure 2. The Relationship between the Brand and Consumer Preference with Structural Equations Modelling}

The revised structural equation model reveals that, the indicator has a significant relationship with latent variable $(p<0.5)$. It was found that, brand variable positively correlated with consumer preference $(p<0.5)$. Moreover, income level positively correlated with consumer preference $(p<0.5)$. As a result, research hypotheses $H_{1}$ was supported.

According to the abovementioned results, brand and consumer preference have been found significantly associated $(P<0.001)$. In this context, the relationship weight of brand and consumer preference (standardized regression weight) was 0.28 . Consequently, brand variable explain $10 \%$ of the change (variance) on consumer preference. As a result; the value $(\mathrm{Z1})$ is \% 90 . 


\section{Discussion and Conclusion}

The purpose of this study was to examine the relationship between brand and consumer preference with Structural Equation Model in Turkmenistan.

This study reveals several attractive findings that merit further discussions. The findings are also in line with previous findings in brand and consumer decision making studies (Matsatsinis \& Samaras, 2000; Murthi \& Rao, 2012; Venkatraman, et al., 2012; Diels, Wiebach, and Hildebrandt, 2013; Romani, Grappi, \& Dalli, 2012).The results of this study provide support for the concept that brand variable effects consumer's preferences. The SEM results of this study revealed that the hypothesis one $(\mathrm{H} 1)$ has a statistically significant relationship with a positive regression coefficient of .28. This finding illustrates that, brand name of a product has more likely a strong impact on the decision making process of a consumer. This implies that brand creates consumer awareness and desirability that can facilitate consumer decision making and activate brand purchase. Peoples brand experiences built consumer's preferences toward certain brands directly or indirectly.

Overall, the results of this study indicated that brand image has positive and significant impact on consumer preferences. By drawing the attention of practitioners to the key factors underlying brand effects, the result of this study may also provide a bridge from theory to business practice and inspire managers to create functionally useful, meaningful and culturally relevant brands. This study provides a useful source of information for academic researchers and business practitioners who wish to conduct research and/or manage workers in Turkmenistan. Also, Managers should have lessons to learn from this study that, they should go beyond if they are to optimize people-centered business advantage in the marketplace by putting more emphasis on branding due to the perception that people are more tend to have products with reputable brand names.

This study recommends several points for future research. These recommendations are retrieved from the analyses of the results of this study. Brand and consumer preferences may not be fully explained with the dimensions used in this study. Consequently, deeply examining the dimensions of brand and consumer preferences would be an important contribution and a potential topic for future research. Finally, it is also recommended that more research on the relationships between brand and consumer preferences be conducted in Turkmenistan to understand consumer behaviors.

\section{References}

Ainslie, A., \& Rossi, P. E. (1998). Similarities in Choice Behavior Across Product Categories. Marketing Science, 17(2), 91-106.

Byrne, B. M. (2010). Structural Equation Modeling with AMOS: Basic concepts, applications, and programming. Ed. 2, Routledge: Taylor \& Francis Group, New York, NY

Byrne, B. M. (2001). Structural Equation Modeling with AMOS: Basic Concepts, Applications, and Programming. Mahwah, N.J.: Lawrence Erlbaum Associates. 
Cătălin, M. C., \& Andreea, P. (2014). Brands as a Mean of Consumer Self-expression and Desired Personal Lifestyle. Procedia - Social and Behavioral Sciences, 109, 103-107. http://dx.doi.org/10.1016/j.sbspro.2013.12.427

Diels, J. L., Wiebach, N., \& Hildebrandt, L. (2013). The Impact of Promotions on Consumer Choices and Preferences in Out-of-Stock Situations. Journal of Retailing and Consumer Services, 20(6), 587-598. http://dx.doi.org/10.1016/j.jretconser.2013.04.009

Gabor, M. R., \& Conţiu, L. C. (2012). Is Dacia-Logan Car Brand on the First Place of Romanian Youth Preferences? Testing the Influence of Advertising Campaigns with Nonparametric Statistics. Procedia-Social and Behavioral Sciences, 58, 1344-1352.

http://dx.doi.org/10.1016/j.sbspro.2012.09.1118

Ge, X., Brigden, N., \& Häubl, G. (2015). The Preference-Signaling Effect of Search. Journal of Consumer Psychology, 25(2), 245-256. http://dx.doi.org/10.1016/j.jcps.2014.09.003

Güngör, M. Ö. \& Bilgin, F. Z. (2011). Customer's Advisory, Organizational Openness and Capability: the Locus of Value Creation. Eurasian Journal of Business and Economics, 4 (7), 81-97.

Jin, X., \& Weber, K. (2013). Developing and Testing a Model of Exhibition Brand Preference: The Exhibitors' Perspective. Tourism Management, 38, 94-104.

http://dx.doi.org/10.1016/j.tourman.2013.02.018

Isik, A., (2013) Effect of Consumer Behavior in Turkmenistan, Interdisciplinary Trends in Science and Technology, 164-172.

Kline, R. B. (2011). Principles and Practice of Structural Equation Modeling, Ed. 3. New York, NY: The Guilford Press.

Kula, S. (2011), Occupational Stress and Work-Related Wellbeing of Turkish National Police (TNP) Members, University of Central Florida, Orlando (unpublished dissertation).

Matsatsinis, N. F., \& Samaras, A. P. (2000). Brand Choice Model Selection Based on Consumers' Multicriteria Preferences and Experts' Knowledge. Computers \& Operations Research, 27(7-8), 689-707. http://dx.doi.org/10.1016/S0305-0548(99)00114-8

Mindrut, S., Manolica, A., \& Roman, C. T. (2015). Building Brands Identity. Procedia Economics and Finance, 20, 393-403. http://dx.doi.org/10.1016/S2212-5671(15)00088-X

Murthi, B., \& Rao, R. C. (2012). Price Awareness and Consumers' Use of Deals in Brand Choice. Journal of Retailing, 88(1), 34-46. http://dx.doi.org/10.1016/j.jretai.2011.07.001

Romani, S., Grappi, S., \& Dalli, D. (2012). Emotions That Drive Consumers Away from Brands: Measuring Negative Emotions Toward Brands and Their Behavioral Effects. International Journal of Research in Marketing, 29(1), 55-67.

http://dx.doi.org/10.1016/j.ijresmar.2011.07.001

Sheena, \& Naresh, G. (2012). Do Brand Personalities Make a Difference to Consumers? Procedia - Social and Behavioral Sciences, 37, 31-37.

Sahin, I. (2010). Organizational Social Capital and Perceived Performance of Drug Law Enforcement Departments: A Case Study in Turkey. University of Central Florida, Orlando, FL (unpublished dissertation).

Schmitt, B. (2012). The Consumer Psychology of Brands. Journal of Consumer Psychology, 22, 17-22. http://dx.doi.org/10.1016/j.jcps.2011.09.005 
Schreiber, J. B., Stag F. K. E., King J., Nora A. and Barlow E. A. (2006). Reporting Structural Equation Modeling and Confirmatory Factor Analysis Results: A Review. The Journal of Educational Research, 99 (6), pp. 323-337. http://dx.doi.org/10.3200/JOER.99.6.323-338

Schumacker, R.E and Lomax, R.G. (2004). A Beginner's Guide to Structural Equation Modeling, Second Edition, Lawrence Erlbaum Associates, Publishers, Mahwah, New Jersey.

Spillan, J. E. \& Harcar, T. (2013). A Comparative Study of Patriotism, Protectionism, Social Economic Conservatism between Indian and Vietnamese Consumers: The Effects of these Constructs on Buying Inclinations. Eurasian Journal of Business and Economics, 6 (12), 1-26.

Uryan, Y. (2010). Organizational Safety Culture and Individual Safety Behavior: A Case Study of the Turkish National Police Aviation Department, University of Central Florida, Orlando (unpublished dissertation).

Varian, H. R. (2006). Revealed Preference. Samuelsonian Economics and the Twenty-First Century, 99-115. http://dx.doi.org/10.1093/acprof:oso/9780199298839.003.0007

Veloutsou, C., \& Moutinho, L. (2009). Brand Relationships Through Brand Reputation and Brand Tribalism. Journal of Business Research, 62(3), 314-322. http://dx.doi.org/10.1016/j.jbusres.2008.05.010

Venkatraman, V., Clithero, J. A., Fitzsimons, G. J., \& Huettel, S. A. (2012). New Scanner Data for Brand Marketers: How Neuroscience Can Help Better Understand Differences in Brand Preferences. Journal of Consumer Psychology, 22(1), 143-153.

http://dx.doi.org/10.1016/j.jcps.2011.11.008 